\title{
OPEN Development and validation of a gas chromatography method for the determination of $\beta$-caryophyllene in clove extract and its application
}

\author{
Mi Hee Park, Chul Jin Kim, Jin Young Lee, In Seon Kim \& Sung-Kyu Kim ${ }^{\varpi}$
}

The purpose of this study is to check the effectiveness of the analysis method that separates and quantifies $\beta$-caryophyllene among clove extracts and validate according to current ICH guidelines. The $\beta$-caryophyllene was active constituent of clove buds. The developed method gave a good detection response. In the specificity test, the standard solution was detected at about $17.32 \mathrm{~min}$, and the test solution was detected at $17.32 \mathrm{~min}$. The linearity of $\beta$-caryophyllen was confirmed, and at this time, the correlation coefficient $\left(R^{2}\right)$ of the calibration curve showed a high linearity of 0.999 or more in the concentration range. The levels of LOD and LOQ were $1.28 \mathrm{ug} / \mathrm{mL}$ and $3.89 \mathrm{ug} / \mathrm{mL}$, respectively. The accuracy was confirmed to be 101.6-102.2\% and RSD $0.95 ~ 1.31 \%$. As a result of checking the repeatability and inter-tester reproducibility to confirm the precision, the RSD was found to be 1.34 2.69\%. This validated GC method was successfully applied to a soft capsule containing clove extract and other materials for clinical trials. Therefore, this method can be used as an analytical tool for quality control of various samples, including clove extracts and their products of food and pharmaceutical uses.

The preparation of functional materials and pharmacological products requires the development of good validated methods to ensure its quality, efficacy and safety within different samples. For that, the validation should be completed to confirm that an analytical method is selective, robust, accurate and reproducible at the specified range ${ }^{1}$. To perform the method validation, it is recommended to follow the guidelines on the regulatory agencies $^{2}$. Mandatory Criteria for the quality of natural compounds, pharmaceuticals, foods, cosmetics, and other products are ensured by method validation ${ }^{3}$. Regarding development of therapeutic or functional agents of plans, a validated analytical method is required at every step. Among other things, it is necessary at the step of the quantification of the active compounds in biological components for tracking preclinical and clinical analysis ${ }^{4}$. Moreover, the manufacturing conditions of active pharmaceutical ingredients require proper quality control of the various ingredients involved in the synthesis ${ }^{5}$. The permissible limit of these materials is given in the ICH guidelines ${ }^{6}$.

In this study, we developed and validated analytical method of the estimation of $\beta$ - caryophyllene in clove extracts to applicates for functional materials according to ICH guidelines. Actually, $\beta$-caryophyllene is present in a various plant species such as cloves, cinnamon leaves, copaiba balsam and basil, and a natural bicyclic sesquiterpene ${ }^{7}$ It is a main ingredient in various essential oils obtained from a number of plant species such as the Strobilanthes $(\sim 7 \%)$, Syzygium $(\sim 13 \%)$ and Betula $(\sim 30 \%)$ species $^{8-10}$. It has been known to have antimicrobial, anti-inflammatory, anticancer and antioxidant effects ${ }^{11-14}$. Clove extract oil is produced by extraction from the dried clove buds of the clove plant. Traditionally, it has been applied as a flavouring spice in foods as a fragrance ${ }^{15,16}$. It is also found in topical analgesics. The US Food and Drug Administration (FDA) categorizes clove oil or its components as generally recognized as safe (GRAS) for the purpose of dental cement use or food additive use ${ }^{17}$. In MFDS (Ministry of Food and Drug Safety), the clove buds are classified as a food ingredient. Clove bud is categorized a fragnant plant in vegetable raw materials ${ }^{18}$. Clove represents great potential for pharmaceutical, food, cosmetic and agricultural applications ${ }^{19}$. 
Several study has been reported that $\beta$-caryophyllene was effective on various diseases including cancer, inflammatory disease and neurodegenerative diseases. $\beta$-caryophyllene suppresses ovarian cancer proliferation by inducing apoptosis and cell cycle arrest ${ }^{20} . \beta$-caryophyllene also induces G1 phase cell cycle arrest in lung cancer cells ${ }^{21}$. $\beta$-caryophyllene also induces apoptosis in skin cancer cells including A431 and HaCaT cells by synergistic interaction with aromadendrene oxide 2 and phytol $^{22}$. $\beta$-caryophyllene from cloves extract inhibited $H$. pylori growth via via the downregulation of $\mathrm{dnaE}, \mathrm{dnaN}$, holB, and gyrA and also downregulated virulence factors such as CagA, VacA, and SecA proteins. Moreover, $\beta$-caryophyllene eradicates ${ }^{23}$. H. pylori in Mouse Model and the effect was similar with triple therapy ${ }^{24}$. $\beta$-caryophyllene also has an effect on inflammatory bowel disease by critical mechanisms ${ }^{13,25}$. $\beta$-caryophyllene attenuates DSS-induced colitis, by modulating the expression of genes associated mainly with colon inflammation through inhibition of DSS-induced NF- $\kappa \mathrm{B}$ activity. In that experiment, $\beta$-caryophyllene reduces the expression of inflammation-related genes including cytokines and chemokines (Ccl2, Ccl7, Ccl11, Ifitm3, IL-1 $\beta$, IL-28, Tnfrsf1b, Tnfrsf12a); acute-phase proteins (S100a8, Saa3, $\mathrm{Hp}$ ); adhesion molecules (Cd14, Cd55, Cd68, Mmp3, Mmp10, Sema6b, Sema7a, Anax13); and signal regulatory proteins induced by DSS. Moreover, oral administration of $\beta$-caryophyllene significantly reduced the inflammation of colon and reversed the increase in MPO activity and level of IL- 6 protein in the tissue ${ }^{13,25}$. $\beta$-caryophyllene is also effective on neurodegenerative diseases. $\beta$-caryophyllene exerts protective antioxidant effects through the activation of NQO1 in the MPTP model of Parkinson's disease ${ }^{26}$. Trans-caryophyllene also inhibits amyloid $\beta$ $(\mathrm{A} \beta)$ oligomer-induced neuroinflammation in BV-2 microglial cells ${ }^{27}$. Moreover, $\beta$-Caryophyllene ameliorates the Alzheimer-like phenotype in APP/PS1 Mice through CB2 receptor activation and the PPAR $\gamma$ pathway ${ }^{28}$.

So, we will apply this material for therapeutic uses. For that, we developed the validation of methods to ensure its quality, safety and efficacy in this work. The method was effectively validated according to the contents: linearity, limit of detection and quantification, selectivity, precision and accuracy. The application of the developed method of commercial formulations containing clove extract will be very satisfactory.

\section{Results}

Method validation. The validation of the optimized method was performed in accordance with the ICH guidelines. The following parameters were considered: specificity, Linearity, Limit of detection (LOD), limit of quantification (LOQ), Accuracy, Recovery and Precision.

Specificity. The $\beta$-caryophyllene of test solution and standard solution was detected at about $17.32 \mathrm{~min}$, and that of test solution was detected at $17.32 \mathrm{~min}$. The chromatograms of the standard solution and test solution are as shown in Fig. 1.

Linearity, limit of detection (LOD) and limit of quantification (LOQ). As for the standard solution, $25 \mathrm{mg}$ of the standard was dissolved in ethanol in a $25 \mathrm{~mL}$ diaphragm flask, and the diaphragm was sequentially diluted with ethanol, and samples of 5.04 to $201.6 \mathrm{ug} / \mathrm{mL}$ were analyzed by the instrument. As a result, the linearity of $\beta$-caryophyllen was confirmed, and at this time, the correlation coefficient $\left(\mathrm{R}^{2}\right)$ of the calibration curve showed a high linearity of 0.999 or more in the concentration range (Table 1 and Supplementary data1). The detection and quantification limit is the value obtained by multiplying the standard deviation of the y-intercept by 3.3 times the standard deviation of the $y$-intercept by the average value of the slope using the calibration curve analyzed three times as the detection limit, and quantifying the value divided by the average value of the slope of the value multiplied by 10 times. It was set as the limit. As a result, the levels were $1.28 \mathrm{ug} / \mathrm{mL}$ and $3.89 \mathrm{ug} / \mathrm{mL}$, respectively.

Accuracy and recovery. In order to measure the accuracy of $\beta$-caryophyllene in the clove extract, the matrix effect was examined through the percentage recovered by spiking/recovery at different concentrations of the sample. A certain amount of the sample was collected according to the standard substance addition method, and the concentration of 100,200 , and $400 \mathrm{ug} / \mathrm{mL}$ of standard solution was added and adjusted to $50 \mathrm{~mL}$, diluted appropriately, and the detection concentration was measured. As a result, the recovery rates for each concentration were $101.6 \%, 101.6 \%$, and $102.2 \%$, and the relative standard deviations were $1.31 \%, 1.04 \%$, and $0.95 \%$ (Table 2).

Precision. Repeatability. In order to check the repetition accuracy for the change in the sample amount, samples were taken at $0.1 \mathrm{~g}, 0.5 \mathrm{~g}$, and $1.0 \mathrm{~g}$, respectively, and measured repeatedly 6 times each. As a result of checking the relative standard deviation (RSD) of each concentration, it was found to be $1.34 \sim 2.69 \%$ (Table 3).

Reproducibility. In order to confirm the reproducibility of the analysis of the content of $\beta$-caryophyllene in the clove extract, the analysis was performed with different analysts and analysis dates. As a result of the analysis between experiments, the content of $\beta$-caryophyllene was analyzed as an average of $967.23 \mathrm{mg} / \mathrm{g}$, at which time the standard deviation was $6.03 \mathrm{mg} / \mathrm{g}$ and the relative standard deviation was $0.62 \%$ (Table 4 ).

Real sample analysis. The method was applied for real sample determination. We produced the capsules including $243 \mathrm{mg}$ of clove extract (98\% $\beta$-caryophyllene) and $217 \mathrm{mg}$ of soybean oil in capsule contents, and modified starch, glycerin, carrageenan et al. in capsule film. As shown in Fig. 2 , we detected the $\beta$-caryophyllene in capsule contents by GC anlysis and the data was $238.73 \pm 1.02 \mathrm{mg}$ at $17.32 \mathrm{~min}$. Moreover, we already showed that the $\beta$-caryophyllene in medical foods. We inserted $165.3 \mathrm{mg}$ of clove extract ( $98 \% \beta$-caryophyllene) for H.pylori eradication in the medical foods. After sampling with food, we also detected the $\beta$-caryophyllene about $161.25 \pm 1.54 \mathrm{mg}$ (data not shown), so we suggested that this method can be useful for quality control. 


\section{A. Test solution}

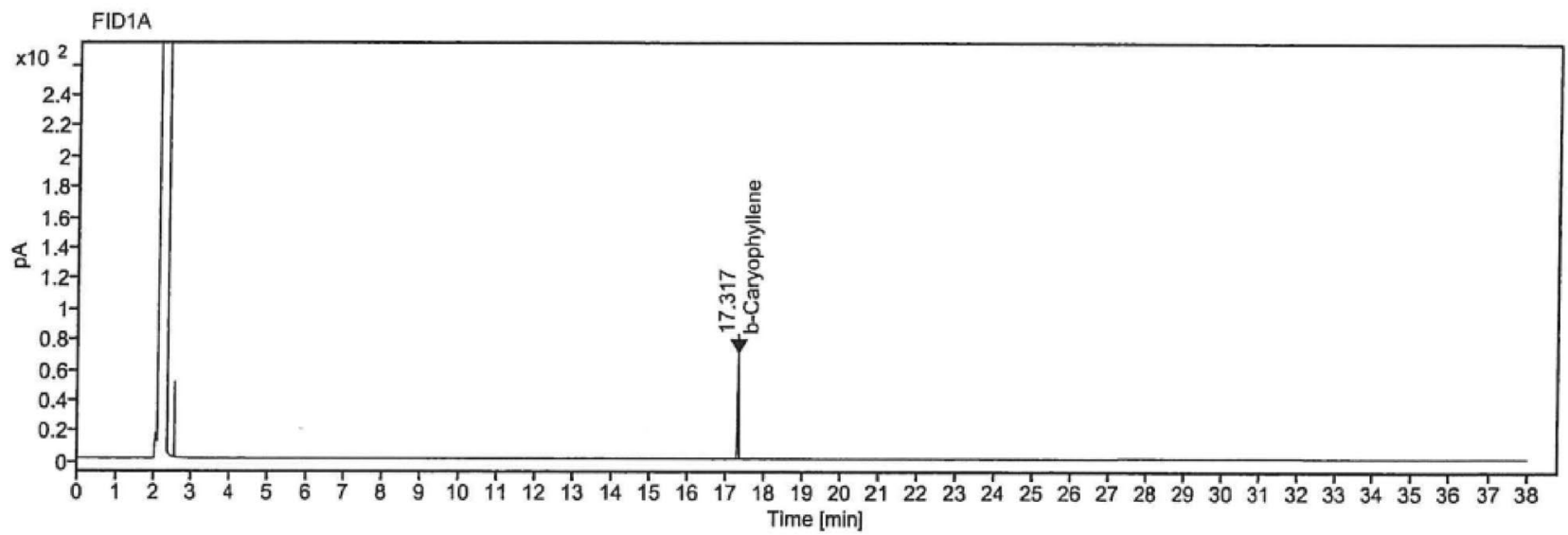

\section{B. Standard solution}

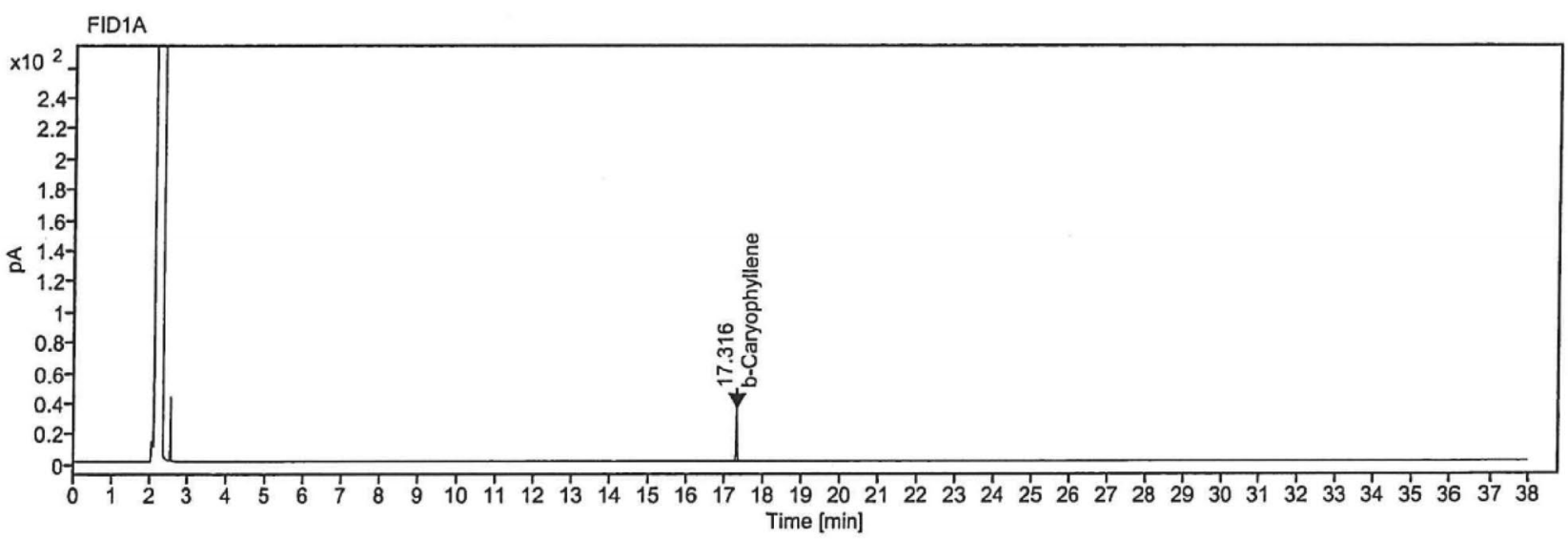

Figure 1. $\beta$-caryophyllene chromatogram of test solution (A) and standard solution (B) . The chromatogram data represents the $\beta$-caryophyllene in clove extracts (test solution) and standard solution ((-)-transCaryophyllene (CAS: 87-44-5 MW: $204.35 \mathrm{~g} / \mathrm{mol}$ ). $\beta$-caryophyllene was detected at about $17.32 \mathrm{~min}$ in test solution, and at $17.32 \mathrm{~min}$ in the standard solution.

\begin{tabular}{|l|l|l|l|l|}
\hline Concentration $(\mathrm{ug} / \mathrm{mL})$ & Regression equation & $\mathbf{R}^{2}$ & LOD $(\mathrm{ug} / \mathrm{mL})$ & LOQ $(\mathrm{ug} / \mathrm{mL})$ \\
\hline $5.04-201.6$ & $\mathrm{y}=1.31 \mathrm{x}+1.09$ & 0.9996 & 1.28 & 3.89 \\
\hline
\end{tabular}

Table 1. Linearity, Limit of detection (LOD) and limit of quantification (LOQ).

\section{Discussion}

In this study, a gas chromatography (GC) method was developed and validated for the estimation of major chemical marker, $\beta$-caryophyllene in clove extract. GC is the useful analytical technique for essential oil samples. And the ability of the GC method to effectively separate volatiles from a short analysis time is determined by several factors ${ }^{29,30}$. This method has been validated according to ICH guidelines on various parameters, such as specificity, limit of detection, and quantification, linearity, precision and accuracy. The validation parameters tested were found to be within acceptable limits. This method has been successfully applied to the quantification of pharmaceutical formulations.

In this test method, for the determination of $\beta$-caryophyllene in the clove extract, a standard substance and a sample were dissolved in ethanol, extracted, and analyzed by GC chromatography. As a result of GC analysis to confirm the specificity, the detection time was detected at $17 \mathrm{~min}$ for both the standard solution and the sample, and linearity was confirmed with $\mathrm{R}^{2}=0.999$ or more in the range of 5.08 to $201.6 \mathrm{ug} / \mathrm{mL}$ of the standard solution. 


\begin{tabular}{|l|l|l|l|}
\hline \multirow{2}{*}{ Treatment } & \multicolumn{3}{|l|}{ Spiked Conc.(ug/mL) } \\
\cline { 2 - 4 } & $\mathbf{1 0 0}$ & $\mathbf{2 0 0}$ & $\mathbf{4 0 0}$ \\
\hline 1 & 1062.9 & 1195.65 & 1394.46 \\
\hline 2 & 1082.26 & 1175.21 & 1383.17 \\
\hline 3 & 1093.58 & 1166.55 & 1406.98 \\
\hline 4 & 1067.14 & 1178.61 & 1376.88 \\
\hline Measured mean $(\mathrm{mg} / \mathrm{g})$ & 1076.47 & 1179.00 & 1390.36 \\
\hline \%RSD & 1.31 & 1.04 & 0.95 \\
\hline Recovery mean(\%) & 101.6 & 101.6 & 102.2 \\
\hline
\end{tabular}

Table 2. Accuracy of $\beta$-Caryophyllene.

\begin{tabular}{|l|l|l|l|}
\hline \multirow{2}{*}{ Treatment } & \multicolumn{3}{|l|}{ Sample content $\mathbf{( g )}$} \\
\cline { 2 - 4 } & $\mathbf{0 . 1} \mathbf{g}$ & $\mathbf{0 . 5} \mathbf{g}$ & $\mathbf{1 . 0} \mathbf{g}$ \\
\hline 1 & 1026.65 & 950.69 & 969.53 \\
\hline 2 & 950.25 & 953.14 & 948.17 \\
\hline 3 & 993.06 & 973.06 & 981.01 \\
\hline 4 & 996.01 & 968.8 & 967.86 \\
\hline 5 & 1018.7 & 963.47 & 969.34 \\
\hline 6 & 1005.16 & 990.47 & 985.47 \\
\hline Measured mean $(\mathrm{mg} / \mathrm{g})$ & 998.3 & 966.61 & 970.22 \\
\hline \%RSD & 2.69 & 1.51 & 1.34 \\
\hline
\end{tabular}

Table 3. Repeatability of $\beta$-Caryophyllene.

\begin{tabular}{|l|l|l|l|l|}
\hline \multirow{2}{*}{} & \multicolumn{4}{|l|}{ Test date and analyst } \\
\cline { 2 - 5 } & \multicolumn{2}{l}{$\begin{array}{l}\text { 2020.10.20., } \\
\text { analyst A }\end{array}$} & \multicolumn{2}{l|}{$\begin{array}{l}\text { 2020.10.23., } \\
\text { analyst B }\end{array}$} \\
\cline { 2 - 5 } & $\mathbf{0 . 5} \mathbf{g}$ & $\mathbf{1 . 0} \mathbf{g}$ & $\mathbf{0 . 5} \mathbf{g}$ & $\mathbf{1 . 0} \mathbf{g}$ \\
\hline 1 & 977.33 & 994.89 & 967.11 & 984.61 \\
\hline 2 & 980.53 & 975.81 & 969.48 & 965.45 \\
\hline 3 & 957.2 & 958.81 & 947.05 & 948.28 \\
\hline 4 & 989.85 & 958.04 & 979.69 & 947.89 \\
\hline 5 & 968.44 & 959.86 & 958.09 & 949.45 \\
\hline 6 & 965.05 & 983.08 & 955.02 & 972.41 \\
\hline Average $(\mathrm{mg} / \mathrm{g})$ & 973.07 & 971.75 & 962.74 & 961.35 \\
\hline \%RSD & 0.62 & & & \\
\hline
\end{tabular}

Table 4. Reproducibility of $\beta$-Caryophyllene.

As a result of reviewing the recovery rate by adding the standard material, the accuracy was confirmed to be $101.6 \sim 102.2 \%$ and RSD $0.95 \sim 1.31 \%$. As a result of checking the repeatability and inter-tester reproducibility to confirm the precision, the average was $978.71 \mathrm{mg} / \mathrm{g}$, and RSD was found to be $1.34 \sim 2.69 \%$.

We applied this method for real sample determination. Actually, we produced the pharmaceutical materials to perform the clinical trials. In the previous study, we showed that the clove extract was effective for the eradication of H.pylori in a mouse model. Based on the concentration of animal study, we calculated the human equivalent dose (HED), and then, the daily intake dose was determined. We manufactured the soft capsule to take twice a day, so one capsule contained about $243 \mathrm{mg}$ of clove extract ( $98 \% \beta$-caryophyllene). We analyzed the $\beta$-caryophyllene concentration of the soft capsule for 3 times, and the $\beta$-caryophyllene was detected at $17.32 \mathrm{~min}$ at a concentration of $238.73 \pm 1.02 \mathrm{mg}$. Moreover, we already showed that the $\beta$-caryophyllene in medical foods. We inserted $165.3 \mathrm{mg}$ of clove extract ( $98 \% \beta$-caryophyllene) for H.pylori eradication in the medical foods. After sampling with food, we also detected the $\beta$-caryophyllene about $161.25 \pm 1.54 \mathrm{mg}$ (data not shown). So, this method will be useful for the commercial formulations containing clove extract, especially for applications such as pharmaceutical drugs, functional foods or medical foods.

Other method also estabilished the methods for validation of caryophyllene. However, that method was HPLC method or not an ICH guideline ${ }^{31,32}$. However, GC is the useful analytical technique for essential oil 


\section{\#1 sample : $238.63 \mathrm{mg} / \mathrm{g}$}

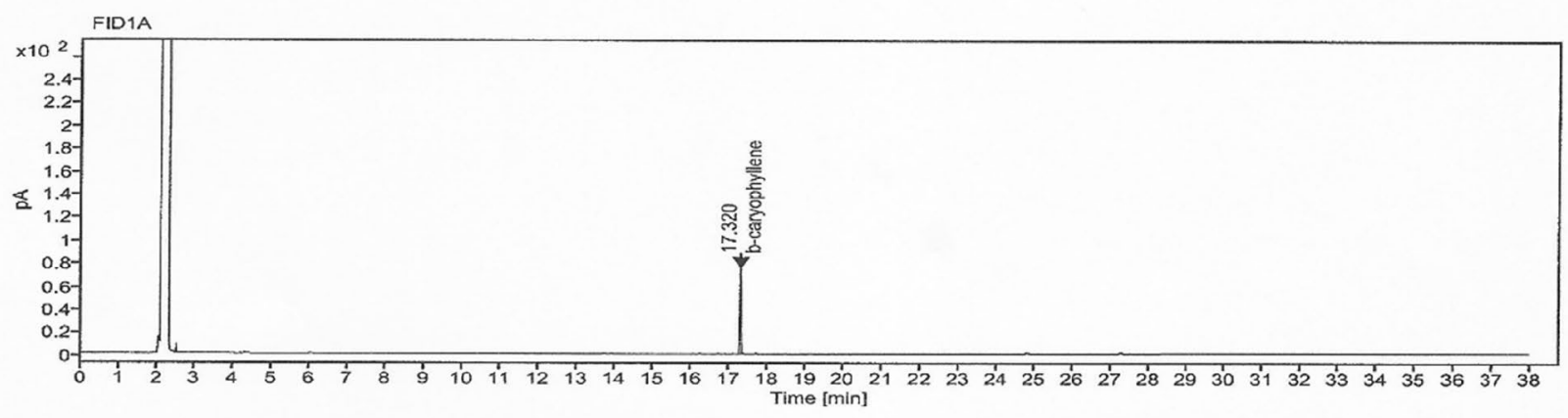

\#2 sample : $237.76 \mathrm{mg} / \mathrm{g}$

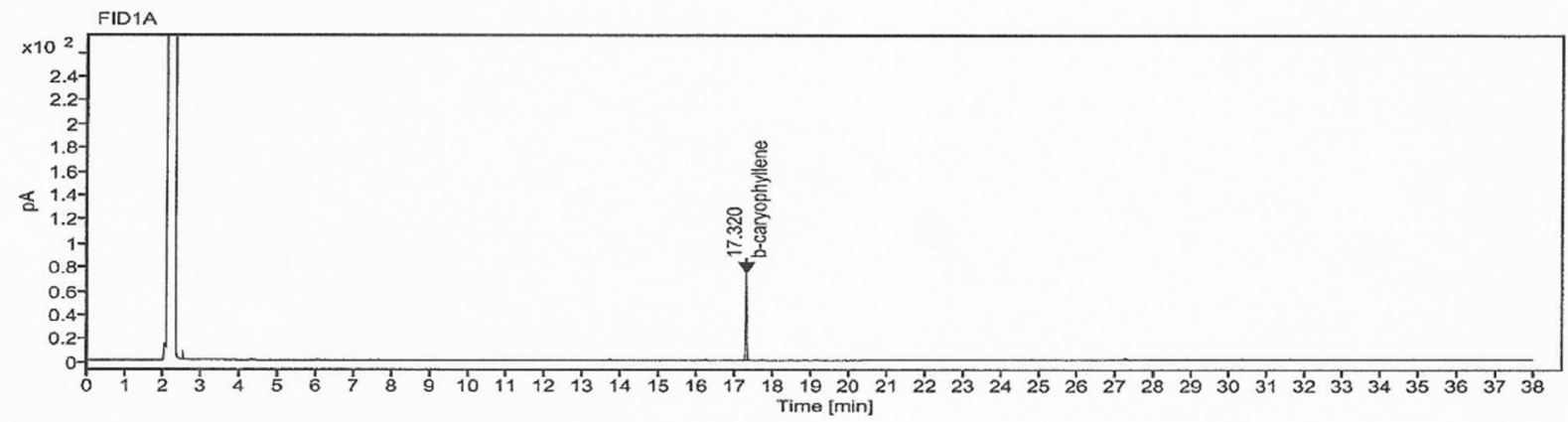

\section{\#3 sample : $239.81 \mathrm{mg} / \mathrm{g}$}

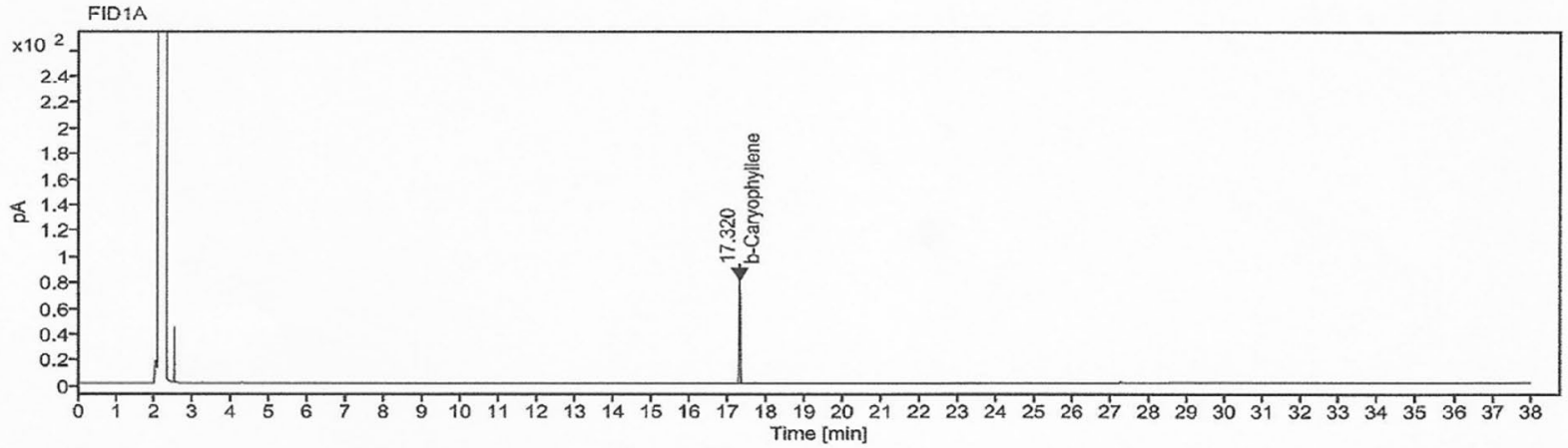

Figure 2. Chromatogram of $\beta$-caryophyllene in soft capsule. $\beta$-caryophyllene was analyzed the in soft capsule contained clove extract, soybean oil in capsule contents, and modified starch, glycerin, carrageenan, et al.in capsule film. The $\beta$-caryophyllene was detected at $17.32 \mathrm{~min}$ at a concentration of $238.73 \pm 1.02 \mathrm{mg}$. 
samples. Moreover, there are no standards and test methods for $\beta$-caryophyllene for permission of medicines or functional foods yet. Several studies suggested that $\beta$-caryophyllene may be useful for therapeutic use for the treatment of cancer, neurodegenerative disease, several inflammatory diseases. So, this method is useful for permission of medicines or functional foods as standards and test methods. We wanted to create internationally accepted standards and analysis methods, and provide useful information to readers who would like to develop pharmaceuticals with caryophyllene in the future.

It is important to point out that $\beta$-caryophyllene appear to be the chemical markers for clove extract because a large diversity of studies involving $\beta$-caryophyllene have been demonstrated with their high potential as antimicrobial, anti-inflammatory, anti-allergic, insecticidal, and anti-plasmodial. Taking into account the importance of the clove extract for the development of new natural products, and its large use for the functional foods and pharmaceutical and cosmetic industries, as well as the lack of validated analytical methods to accurately quantify these compounds in raw material and its products, we report a complete validated method by gas chromatography.

\section{Methods}

Instrumentation andanalytical conditions. A gas chromatography with flame ionization detector (Aglient $8890 \mathrm{~N}(\mathrm{G} 3540 \mathrm{~A})$ ) was used for the determination of $\beta$-caryophyllene in clove extract. All the gases used in these studies were of pharmacopotential purity. The analysis conditions are as shown below.

\begin{tabular}{|l|l|}
\hline Item & Condition \\
\hline Column & $\mathrm{HP}-1(30 \mathrm{~m} \times 0.25 \mathrm{~mm}, 0.25 \mathrm{um})$ \\
\hline Inlet temperature & $240^{\circ} \mathrm{C}$ \\
\hline Column temperature & $50^{\circ} \mathrm{C}(5 \mathrm{~min}) \rightarrow 10^{\circ} \mathrm{C} / \mathrm{min} \rightarrow 280^{\circ} \mathrm{C}(10 \mathrm{~min})$ \\
\hline Detector temperature & $295^{\circ} \mathrm{C}$ \\
\hline Carrier gas and flow & $\mathrm{N}_{2}, 1.0 \mathrm{ml} / \mathrm{min}$ \\
\hline Split ratio & $20: 1$ \\
\hline Injection volume & $1 \mathrm{ul}$ \\
\hline
\end{tabular}

Preparation of clove extract and test solution. Clove extract ( $98 \% \beta$-caryophyllene) was obtained from Bordas (Sevilla, Spain). For the preparation of test solution, after weighing a sample, precisely weigh it in a $50 \mathrm{~mL}$ volumetric flask, add ethanol to extract it, and filter it with a $0.45 \mu \mathrm{m}$ nylon filter and use it as a test solution.

Preparation of standard solution. Take a standard product ((-)-trans-Caryophyllene (CAS: 87-44-5 MW: $204.35 \mathrm{~g} / \mathrm{mol}$ ) and dissolve it in HPLC grade ethanol to prepare it, and dilute it appropriately to use it as a standard solution.

Production of soft capsule. We prepared the soft capsule for clinical study. The capsule was produced in GMP factory (Suheung, Osong, Korea). We produced the capsules including $243 \mathrm{mg}$ of clove extract $(98 \%$ $\beta$-caryophyllene) and $217 \mathrm{mg}$ of soybean oil in capsule contents, and modified starch, glycerin, carrageenan et al. in capsule film. In this study, we analyzed the $\beta$-caryophyllene concentration of the soft capsule.

Test method. Specificity. In order to confirm the specificity, the retention times and degree of separation in the standard and sample were checked. The standard substance and test solution (clove extract containing $98 \% \beta$-caryophyllene) were analyzed by the same method, and the detected peak was confirmed to confirm that the substance was the same.

Linearity, limit of detection (LOD) and limit of quantification (LOQ). As for the standard solution, $25 \mathrm{mg}$ of the standard was dissolved in ethanol in a $25 \mathrm{~mL}$ diaphragm flask, and the diaphragm was sequentially diluted with ethanol, and samples of 5.04 to $201.6 \mathrm{ug} / \mathrm{mL}$ were analyzed by instrument. The detection and quantification limit is the value obtained by multiplying the standard deviation of the y-intercept by 3.3 times the standard deviation of the $y$-intercept by the average value of the slope using the calibration curve analyzed three times as the detection limit, and quantifying the value divided by the average value of the slope of the value multiplied by 10 times.

Accuracy, recovery. In order to measure the accuracy of $\beta$-caryophyllene in the clove extract, the matrix effect was examined through the percentage recovered by spiking/recovery at different concentrations of the sample. A certain amount of sample was collected according to the standard substance addition method, and the concentration of 100,200 , and $400 \mathrm{ug} / \mathrm{mL}$ of standard solution was added and adjusted to $50 \mathrm{~mL}$, diluted appropriately, and the detection concentration was measured.

Precision. In order to check the repetition accuracy for the change in the sample amount, samples were taken at $0.1 \mathrm{~g}, 0.5 \mathrm{~g}$, and $1.0 \mathrm{~g}$, respectively, and measured repeatedly 6 times each. In order to confirm the reproducibility of the analysis of the content of $\beta$-caryophyllene in the clove extract, the analysis was performed with different analysts and analysis dates. 
Received: 8 April 2021; Accepted: 25 May 2021

Published online: 05 July 2021

\section{References}

1. González, A. G. \& Herrador, M. A. A practical guide to analytical method validation, including measurement uncertainty and accuracy profiles. Trends Anal. Chem. 26, 227-238 (2007).

2. Geneva. International Conference on Harmonization (ICH) of Technical Requirements for registration of Pharmaceuticals for Human Use Topic Q2 (R1): Validation of Analytical Procedures: Text and Methodology (2005).

3. Sousa, J. P. B. et al. Validation of a gas chromatographic method to quantify sesquiterpenes in copaiba oils. J. Pharm. Biomed. Anal. 54, 653-659 (2011).

4. Haque, S.M. \& Ratemi, E.S. Drug Development and Analysis Review. Pharm. Chem. J. 50, 837-850 (2017).

5. Fabio, P. et al. The requirements for manufacturing highly active or sensitising drugs comparing good manufacturing practices. Acta Biomed. 90, 288-299 (2019).

6. Olena, G., Oleksii, V., Galina, B., Sergiy, K. \& Liliya, L. Method development and validation for the determination of residual solvents in quinabut API by using gas chromatography. Message 2. Pharmacia 68, 53-59 (2021).

7. Opdyke, D. L. Monographs on fragrance raw materials. Food Cosmet. Toxicol. 11, 1011-1081 (1973).

8. Agarwal, R. B. \& Rangari, V. D. Phytochemical investigation and evaluation of anti-inflammatory and anti-arthritic activities of essential oil of Strobilanthus ixiocephala Benth. Indian J. Exp. Biol. 41, 890-894 (2003).

9. Demirci, B., Baser, K. H., Demirci, F. \& Hamann, M. T. New caryophyllene derivatives from Betula litwinowii. J. Nat. Prod. 63, 902-904 (2000).

10. Prashar, A., Locke, I. C. \& Evans, C. S. Cytotoxicity of clove (Syzygium aromaticum) oil and its major components to human skin cells. Cell Prolif. 39, 241-248 (2006).

11. Pichette, A., Larouche, P. L., Lebrun, M. \& Legault, J. Composition and antibacterial activity of Abies balsamea essential oil. Phytother. Res. 20, 371-373 (2006).

12. Kubo, I. et al. Cytotoxic and antioxidative sesquiterpenoids from Heterotheca inuloides. Planta Med. 62, 427-430 (1996)

13. Cho, J. Y. et al. Amelioration of dextran sulfate sodium-induced colitis in mice by oral administration of beta-caryophyllene, a sesquiterpene. Life Sci. 80, 932-939 (2007).

14. Singh, G., Marimuthu, P., De Heluani, C. S. \& Catalan, C. Antioxidant and biocidal activities of Carum nigrum (seed) essential oil, oleoresin, and their selected components. J. Agric. Food Chem. 54, 174-181 (2006).

15. Drugs.com. (2018)

16. Balch, P.Prescription for nutritional healing. 3rd ed., Avery Publishing 94 (2000)

17. Jasna, I., Suzana, D. B., Dusan, M., Mihailo, R. \& Irena, Z. Evaluation and improvement of antioxidant and antibacterial activities of supercritical extracts from clove buds. J. Funct. Foods 5, 416-423 (2013).

18. Food Code and Food Additive Code in Ministry of Food and Drug Safety

19. Cortés-Rojas, D. F., deSouza, C. R. F. \& Oliveira, W. P. Clove (Syzygium aromaticum): a precious spice. Asian Pac. J. Trop. Biomed. 4, 90-96 (2014).

20. Santhosh, A., Harinee, R., Jivitesh, R. \& Haripriya, D. Beta-caryophyllene suppresses ovarian cancer proliferation by inducing cell cycle arrest and apoptosis. Anticancer Agents Med. Chem. 20, 1530-1537 (2020).

21. Chung, K. S. et al. $\beta$-Caryophyllene in the essential oil from chrysanthemum borealeinduces $\mathrm{G} 1$ phase cell cycle arrest in human lung cancer cells. Molecules 24, 3754 (2019).

22. Pavithra, P. S., Mehta, A. \& Verma, R. S. Synergistic interaction of $\beta$-caryophyllene with aromadendrene oxide 2 and phytol induces apoptosis on skin epidermoid cancer cells. Phytomedicine 47, 121-134 (2018).

23. Jung, D. H. et al. Effect of $\beta$-caryophyllene from cloves extract on helicobacter pylori eradication in mouse model. Nutrients 12, $1000(2000)$.

24. Woo, H. J. et al. Inhibitory effects of $\beta$-Caryophyllene on helicobacter pylori infection in vitro and in vivo. Int. J. Mol. Sci. 21, 1008 (2020).

25. Cho, J. Y. et al. $\beta$-Caryophyllene attenuates dextran sulfate sodium-induced colitis in mice via modulation of gene expression associated mainly with colon inflammation. Toxicol. Rep. 2, 1039-1045 (2015).

26. Flores-Soto, M. E. et al. $\beta$-Caryophyllene exerts protective antioxidant effects through the activation of NQO1 in the MPTP model of Parkinson's disease. Neurosci. Lett. 742, 135534 (2021).

27. Hu, Y., Zeng, Z., Wang, B. \& Guo, S. Trans-caryophyllene inhibits amyloid $\beta$ (A $\beta$ ) oligomer-induced neuroinflammation in BV-2 microglial cells. Int. Immunopharmacol. 51, 91-98 (2017).

28. Yujie Cheng, Y., Dong, Z. \& Liu, S. $\beta$-Caryophyllene ameliorates the Alzheimer-like phenotype in APP/PS1 Mice through CB2 receptor activation and the PPAR $\gamma$ pathway. Pharmacology 94, 1-12 (2014).

29. Marriot, P. J., Shellie, R. \& Cornwell, C. Gas chromatographic technologies for the analysis of essential oils. J. Chromatogr. A. 936, $1-22(2001)$.

30. Fan, S., Chang, J., Zong, Y., Hu, G. \& Jia, J. GC-MS analysis of the composition of the essential oil from Dendranthema indicum Var. aromaticum using three extraction methods and two columns. Molecules. 23, 576 (2018).

31. Sousa, J. P. B. et al. Validation of a gas chromatographic method to quantify sesquiterpenes in copaiba oils. J. Pharm. Biomed. Anal. Actions 54, 653-659 (2011).

32. daSilvaGomesa M.V., daSilvaa J.D., Ribeiroab A.F., Cabrala L.M. \& deSousaa V.P. Development and validation of a quantification method for a-humulene and trans-caryophyllene in Cordia verbenaceaby high performance liquid chromatography. Revista Brasileira de Farmacognosia 29, 182-190 (2019).

\section{Acknowledgements}

This work was supported by the Fostering regional specialized industries+(R\&D)-Promoting regional flagship industries, Korea, under the Ministry of SMEs and startups (R\&D, grant number S2912959).

\section{Author contributions}

P.M.H. wrote the paper and conducted the analysis of the data. K.C.J. contributed to set the analysis methods, L.J.Y. and K.I.S. performed the G.C. experiment. K.S.K. contributed to research planning, in charge of overall research and development of soft capsule product.

\section{Competing interests}

The authors declare no competing interests. 


\section{Additional information}

Supplementary Information The online version contains supplementary material available at https:/doi.org/ 10.1038/s41598-021-93306-5.

Correspondence and requests for materials should be addressed to S.-K.K.

Reprints and permissions information is available at www.nature.com/reprints.

Publisher's note Springer Nature remains neutral with regard to jurisdictional claims in published maps and institutional affiliations.

(c) (1) Open Access This article is licensed under a Creative Commons Attribution 4.0 International cc) License, which permits use, sharing, adaptation, distribution and reproduction in any medium or format, as long as you give appropriate credit to the original author(s) and the source, provide a link to the Creative Commons licence, and indicate if changes were made. The images or other third party material in this article are included in the article's Creative Commons licence, unless indicated otherwise in a credit line to the material. If material is not included in the article's Creative Commons licence and your intended use is not permitted by statutory regulation or exceeds the permitted use, you will need to obtain permission directly from the copyright holder. To view a copy of this licence, visit http://creativecommons.org/licenses/by/4.0/.

(c) The Author(s) 2021 